\title{
Thermal energy storage using stearic acid as PCM material
}

\author{
Janusz T. CIEŚLIŃSKI, Maciej FABRYKIEWICZ
}

DOI: 10.30464/jmee.2018.2.3.217

Cite this article as:

Cieśliński J. T., Fabrykiewicz M. Thermal energy storage using stearic ACID as PCM material. Journal of Mechanical and Energy Engineering, Vol. 2(42), No. 3, 2018, pp. 217-224.

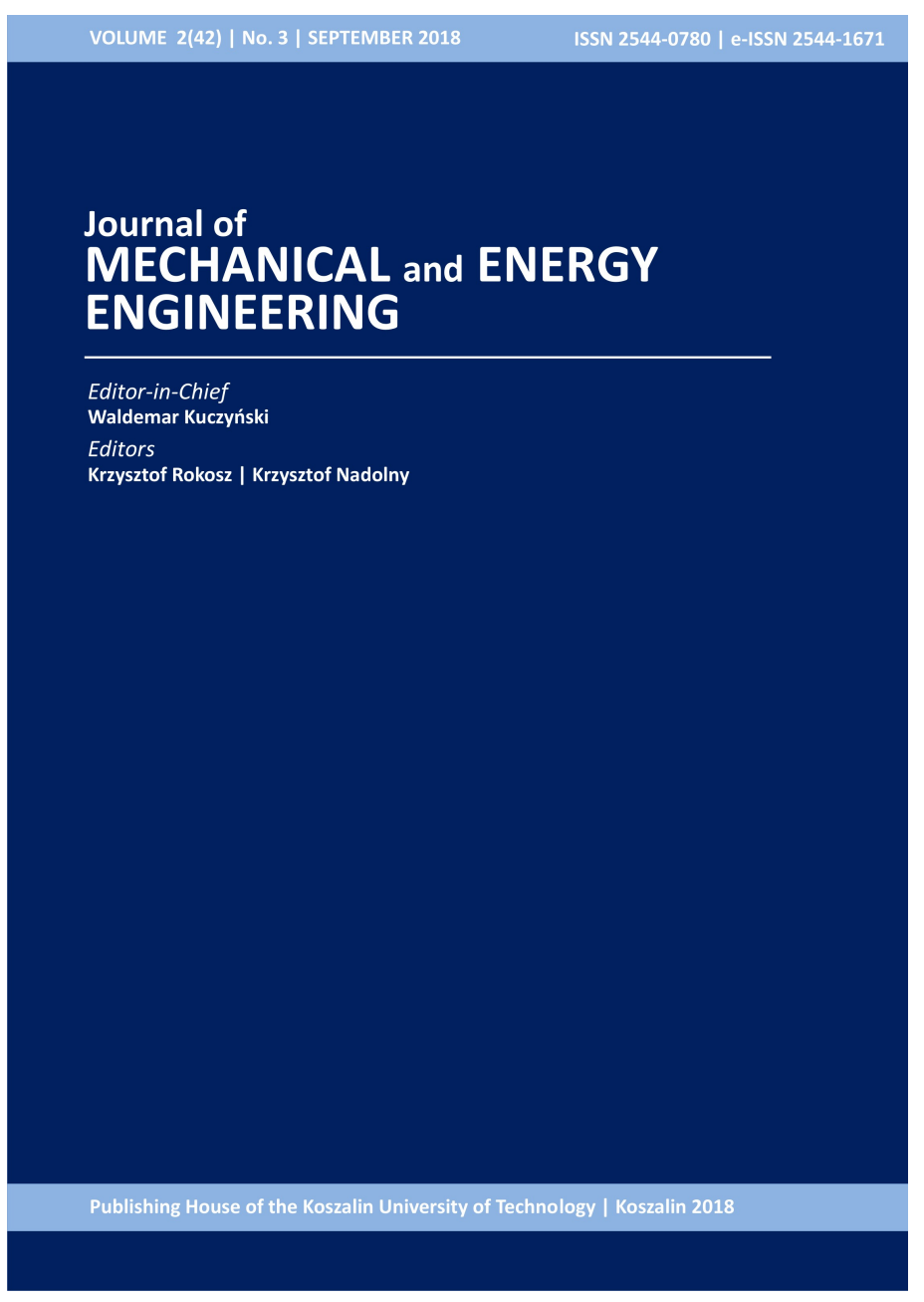

Journal of Mechanical and Energy

Engineering

Website: jmee.tu.koszalin.pl

ISSN (Print): 2544-0780

ISSN (Online): 2544-1671

Volume: 2(42)

Number: 3

Year: 2018

Pages: 217-224

Article Info:

Received 13 August 2018

Accepted 8 September 2018

\section{Open Access}

This article is distributed under the terms of the Creative Commons Attribution 4.0 (CC BY 4.0) International License (http://creativecommons.org/licenses/by/4.0/), which permits unrestricted use, distribution, and reproduction in any medium, provided you give appropriate credit to the original author(s) and the source, provide a link to the Creative Commons license, and indicate if changes were made. 


\title{
THERMAL ENERGY STORAGE USING STEARIC ACID AS PCM MATERIAL
}

\author{
Janusz T. CIEŚLIŃSKI ${ }^{1 *}$, Maciej FABRYKIEWICZ ${ }^{2}$ \\ ${ }^{1 *}$ Faculty of Mechanical Engineering, University of Technology, Narutowicza 11/12, 80-233, Gdańsk, \\ Poland, e-mail: jcieslin@pg.edu.pl \\ ${ }^{2}$ Faculty of Mechanical Engineering, University of Technology, Narutowicza 11/12, 80-233, Gdańsk, Poland, \\ e-mail: falconry@wp.pl
}

(Received 13 August 2018, Accepted 8 September 2018)

\begin{abstract}
This work presents an experimental study of thermal energy storage by the use of PCM. The aim of the study was to establish the influence of the different inlet temperature of heat transfer fluid (HTF) and the different Reynolds number of HTF on the intensity of the charging and discharging processes. The PCM used in this study was stearic acid and water was used as HTF. A copper helical coil mounted in a cylindrical container served as a heat transfer surface.
\end{abstract}

Keywords: PCM, helical coil

\section{INTRODUCTION}

Utilization of renewable sources of energy may be limited by the mismatch between energy supply and energy demand and the intermittent performance of an energy source. Therefore, energy storage plays a crucial role in heat recovery and contributes considerably in improving the performance of thermal systems $[1,2]$. Thermal storage systems are able to store and release heat during the charging or discharging process respectively. There are two main physical ways for thermal energy storage: a change in internal energy of a material as sensible heat or latent heat during phase change process. Sensible heat systems are promising technologies with low heat losses and attractive prices. Commonly used materials for sensible heat storage are fluids, for example: water, glycol, ethylene or oils. The storage based on latent heat has much higher thermal capacity as compared to sensible heat but it is not yet widely commercially viable. The group of materials specific to latent heat storage systems has the common name of phase change materials (PCM's). PCM's include organic, inorganic and eutectic materials. Organic materials are first of all paraffin compounds. Inorganic materials include salt hydrates and metallic and eutectics cover organic-organic, inorganic-inorganic and inorganicorganic compounds [3]. A large number of PCM in any required melting temperature is available. There are known numerous problems with organic and inorganic PCM's like corrosion, phase segregation or flammability but the crucial problem is low thermal conductivity leading to slow charging and discharging rates. Performance of latent heat thermal energy storage (LHTES) systems can be enhanced by applying heat transfer enhancement methods. The novel concept is the application of nanoparticles in a PCM base to obtain the so-called nanocomposites $[4,5]$.

$\mathrm{Wu}$ et al. [6] tested an n-tetradecane as a PCM. The effect of the variations of the phase change material temperature, heat transfer fluid temperature, melt fraction and cool release rate with time during the discharging process werewere determined. Desgrosseilliers et al. [7] established that the influence of a lauric acid of the purity reagent grade [98\% pure] compared with practical grade $[<80 \%$ pure] on the melting transition was insignificant. The long-term stability of the melting transition of practical-grade lauric acid was investigated by thermal cycling of samples from completely solid through completely melting and back to the solid phase, nearly 500 times. Al-Abidi et al. [8] investigated the application of a triplex tube heat exchanger with a paraffin wax RT 82 in the middle tube to power a liquid-desiccant airconditioning system. They examined the effects of mass flow rates and heating methods selected on PCM melting. Three techniques were investigated: heating the inside of thetube, heating the outside of the tube, and heating both sides of the tube. The results indicated that both sides heating achieved complete PCM melting within a short time and used a lower 
inlet HTF temperature compared with other cases. Shokouhmand and Kamkari [9] presented an experimental effort to visualize the temperature field and melt front evolution during solid-liquid phase change process. Their study focused on the melting of a lauric acid in a rectangular thermal storage unit heated from one side. Silakhori et al. [10] tested a mixture of palmitic acid and polypyrrole form-stable PCMs prepared by an in situ polymerization method. Palmitic acid was used as a thermal energy storage material and polypyrrole was operated as a supporting material. Form-stable PCMs were investigated by scanning electron microscopy and FTIR Fourier transform infrared spectrometer analysis that illustrated palmitic acid particles that were wrapped by polypyrrole particles. X-ray diffractometer was used for the crystalline phase of mixture composites. A thermogravimetry analysis and differential scanning calorimetry were used for investigating the thermal stability and thermal energy storage properties of prepared form-stable PCMs. Hosseini et al. [11] carried out experimental and numerical study to establish the thermal behavior and heat transfer characteristics of paraffin RT50 as a PCM during constrained melting and solidification processes inside a shell and tube heat exchanger. A series of experiments were conducted to investigate the effects of increasing the inlet temperature of HTF on the charging and discharging processes of the PCM. Behzadi and Farid [12] presented the thermal characteristic of propyl stearic and palmitate mixture and commercial PCM of Rubitherm 21 with a melting point in the range of $18-25^{\circ} \mathrm{C}$ after an exposure to the storage temperatures of 30 and $55^{\circ} \mathrm{C}$. Zhang et al. [13] prepared eutectic molten salt (50 wt\% NaNO3, 50 wt\% KNO3) as PCM with a melting temperature of about $220^{\circ} \mathrm{C}$. Oil was used asa HTF . Various heating and cooling temperatures were employed in the study, so as to extensively reveal the heat transfer characteristics during heat storage and retrieval. Diao et al. [14] investigated a new-type flat micro-heat pipe thermal storage unit, which uses a moderatetemperature paraffin as a PCM. The basic structure, working principle, and oil design concept of the thermal storage unit were discussed. Experiments were conducted to study the charging and discharging heat transfer processes of the thermal storage unit under different inlet temperatures and flow rates for the cold/hot HTF. Delgado et al. [15] examined a commercial tank with a helical coil heat transfer surface and containing a low cost PCM emulsion. The phase change material emulsion tank presents an energy density $34 \%$ higher than the water tank, which makes it a promising solution. Cano et al. [16] presented experimental investigation of four commercially available PCM's. The influence of the heat transfer fluid flow rate on the performance of the shell and tube heat exchanger was established. Korti and Tlemsani [17] carried out experimental study with three types of paraffin as PCM. The temperatures of PCM and heat transfer fluid, solid fraction and thermal effectiveness were analyzed. The effects of inlet temperature, flow rate and the type of PCM used on the time for charging and discharging heat were discussed. The copper helical coil was used as a heat transfer surface. Motahar and Khodabandeh [18] studied the melting and solidification behavior of PCM using a heat pipe. The experiments were performed using a constant temperature thermal reservoir to provide constant temperatures above and below the melting point for heating and cooling. As PCM, n-octadecane (CH3 (CH2)16CH3) was used with the melting point of $28^{\circ} \mathrm{C}$. Wang et al. [19] studied experimentally a vertical shell-and-tube LHTES unit with an erythritol as storage media and air as HTF. The thermophysical properties of erythritol, such as melting temperature, melting enthalpy, thermal conductivity, and viscosity, were obtained. It was established that during charging, the molten PCM first occupies the top region and then spreads from top to bottom. During discharging, the PCM initially solidifies from the bottom region, and then the solidliquid interface progresses uniformly from the inner tube to the outer shell, where natural convection plays a dominant role in the heat transfer at the liquid region. Moreover, the inlet temperature and the mass flow rate of HTF during charging process were determined. D'avignon and Kummert [20] carried out an experimental study to assess the performance of LHTES in various operating conditions. A horizontal PCM tank contained stacks of slab-like PCM capsules between which HTF could circulate. The commercially available capsules were instrumented so the PCM behavior could be measured in addition to that of the PCM tank as a whole. Numerous melting and solidification cycles were completed with different inlet fluid temperatures, flow rates and load profiles for which at least three repetitions were made. The PCM contained in the capsules is a heterogeneous salt hydrate named S27.

Agarwal and Sarviya [21] examined a shell and tube LHTES unit for a solar dryer. Paraffin wax was used as PCM. The heat transfer characteristics of the LHTES werewere evaluated during the charging and discharging process using air as HTF. Experiments were conducted to study the effects of the flow rate and temperature of HTF on the charging and discharging process. The temperature distributions along the radial and longitudinal directions were obtained at different time during the charging process to analyze the heat transfer phenomenon in the LHTE system. Tayssir et al. [22] examined experimentally a tube-in-tank LHTE system with paraffin wax as PCM. Experiments were performed for different inlet 
temperatures and for different volume flow rates of HTF. A copper helical coil was used as the heat transfer surface. Zondag et al. [23] studied a lab scale shell-and-tube LHTE unit filled with PCM. Moreover, the experimental results were compared with a numerical model. When comparing two PCMs used in the study (RT70 and $\mathrm{MgCl} 2 \cdot 6 \mathrm{H} 2 \mathrm{O}$ ), it was found that the RT70 had stable performance while the salt hydrate showed a reduced melting enthalpy which was ascribed to phase separation. It was established that natural convection in the PCM significantly influences the local temperature distribution in the storage vessel, which could not be predicted well by the model, since the model assumes only conductive heat transport in the PCM. Neumann et al. [24] conducted thermal cycling stability tests of D-mannitol and its effect on melting enthalpy. Short-term cycling tests were carried out in a differential scanning calorimeter in combination with air and nitrogen/vacuum as the atmosphere. The results show that melting enthalpy decreases in contact with oxygen, it decreases less in vacuum and stays almost constant in nitrogen atmosphere over the performed cycles. Moreover, melting enthalpy decreases by about $9 \%$ during 500 cycles. Kabeel et al. [25] investigated the influence of different PCM's on the performance of conventional solar still. In addition, economical studies for all the selected PCMs were performed. Kabbara et al. [26] studied experimentally heat transfer in a coil-in-tank heat exchanger with dodecanoic acid as PCM. The influence of HTF inlet temperature and flow rate was investigated in particular. It was found that during the initial periods of charging conduction was the main mode of heat transfer, while natural convection played an important role once significant melting had occurred in the tank.

The aim of the present paper is an experimental investigation of the influence of the inlet temperature of heat transfer fluid (HTF) and the Reynolds number of HTF on the intensity of the charging and discharging process for a helical coil-in-cylindrical tank LHTE system using stearic acid as a PCM.

\section{EXPERIMENTAL STAND}

The experimental setup used in the study consists of a test container, an inlet and outlet temperature measurement system and a heating or cooling loop equipped with a thermostat, a circular pump and set of control valves. Figure 1 shows the view and Fig. 2 the scheme of the experimental stand. A well insulated test container consists of a cylindrical vessel produced from acrylic glass with $200 \mathrm{~mm}$ OD and $500 \mathrm{~mm}$ length. As a HTF is used water which is prepared in a thermostat. K-type thermocouples are used to measure the inlet and outlet temperature of HTF. Commercially available cooper tubes with $12 \mathrm{~mm}$ OD and $1 \mathrm{~mm}$ wall thickness were used to fabricate the helical coil. The diameter and pitch coil of the tested helical coil are $122 \mathrm{~mm}$, and the coil length is 450 $\mathrm{mm}$. The volume of latent heat thermal energy storage was 15 l. Fig. 3 shows the view of the tested LHTE system with insulation.

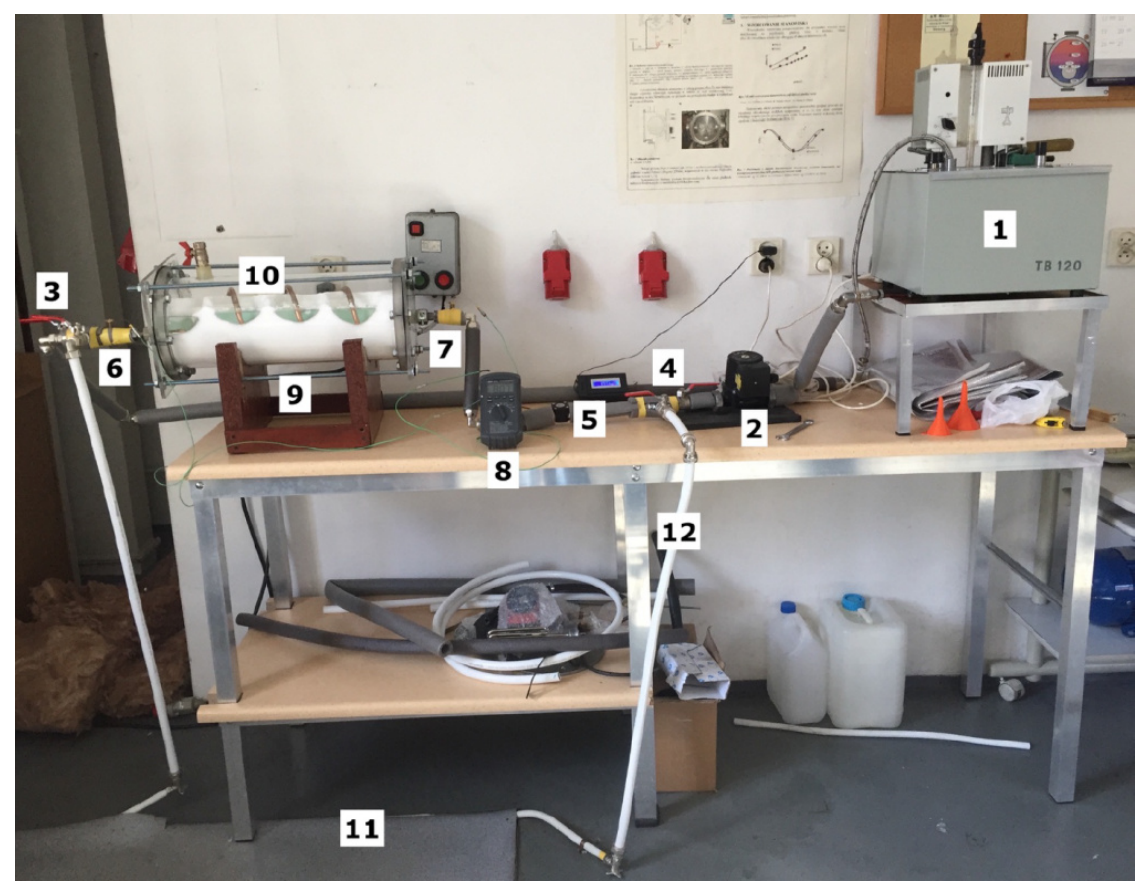

Fig. 1. View of the experimental stand; 1 - thermostat; 2 - circulator pump; 3,4 - set of valves; 5 - flowmeter; 6, 7 - thermocouples; 8 - temperature recorder; 9, 10 - LHTE filled with PCM, 11, 12 - tap water system 


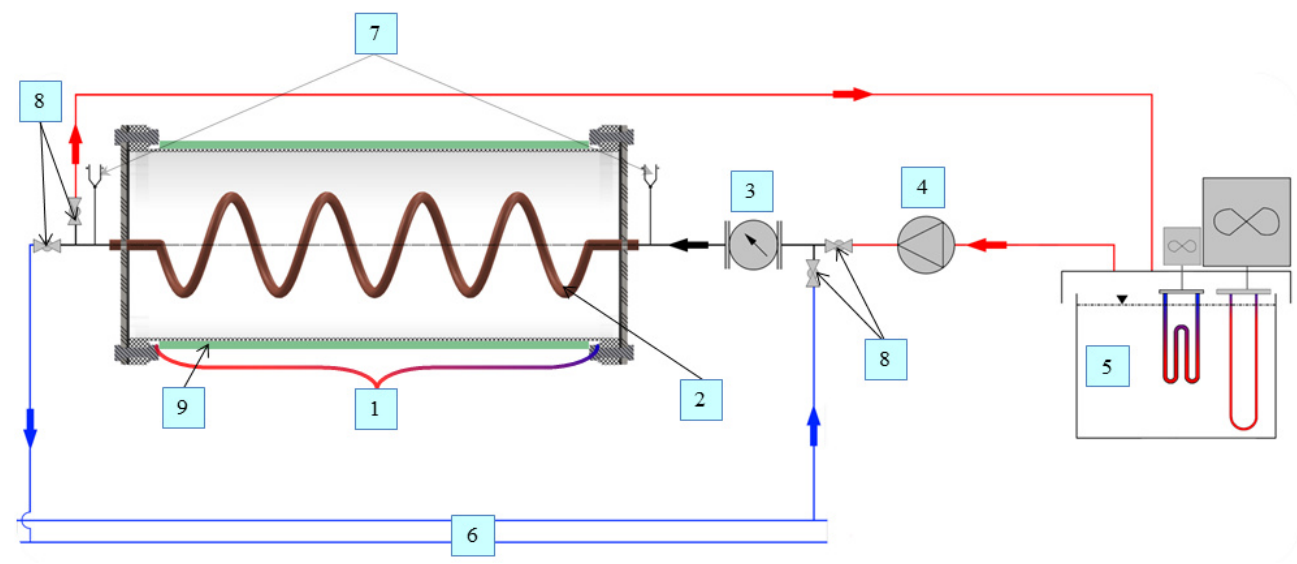

Fig. 2. Schematic diagram of the experimental apparatus; 1 - test container; 2 - helical coil; 3 - flowmeter; 4 - circulator pump; 5 - thermostat; 6 - tap water; 7 - thermocouples; 8 - set of valves; 9 - insulation

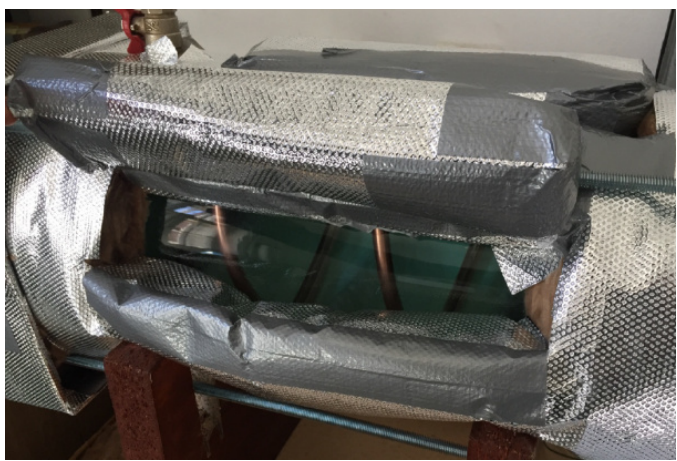

Fig. 3. View of the tested LHTE system

\section{DATA REDUCTION}

Heat flux is calculated as:

$$
\dot{q}=\frac{\dot{Q}}{A},
$$

where the heat transfer rate $\dot{Q}$ is calculated using the measured volume flow rate $\dot{V}$ and the measured temperatures at the inlet $t_{1}$ and outlet $t_{2}$ of the helical coil:

$$
\dot{Q}=\dot{V} \cdot \rho \cdot c_{p} \cdot\left(t_{1}-t_{2}\right),
$$

where $\rho$ and $c_{p}$ are density and the specific heat of the $\mathrm{HTF}$, respectively.

Reynolds number $R e$ is estimated using the formula:

$$
R e=\frac{w \cdot d}{v},
$$

where $d$ is the inside diameter of the helical coil and the velocity $w$ of the HTF is calculated as:

$$
w=\frac{4 \cdot \dot{V}}{\pi \cdot d^{2}}
$$

The uncertainty of the heat transfer surface area was estimated by mean-square method

$$
\Delta A=\sqrt{\left(\frac{\partial A}{\partial D} \Delta D\right)^{2}+\left(\frac{\partial A}{\partial L} \Delta L\right)^{2}},
$$

where the absolute measurement errors of the diameter $\Delta D$ and length $\Delta L$ of the helical coil are 0.00001 $\mathrm{m}$ and $0.001 \mathrm{~m}$, respectively. The experimental limit of error for the heat transfer surface area is $\pm 0.1 \%$.

The uncertainty of the heat flux was estimated by the mean-square method:

$\Delta \dot{q}=\sqrt{\left(\frac{\partial q}{\partial \dot{V}} \Delta \dot{V}\right)^{2}+\left(\frac{\partial q}{\partial \rho} \Delta \rho\right)^{2}+\left(\frac{\partial q}{\partial c_{p}} \Delta c_{p}\right)^{2}+\left(\frac{\partial q}{\partial \Delta t} \delta \Delta t\right)^{2}+\left(\frac{\partial q}{\partial A} \Delta A\right)^{2}}$

where the absolute measurement errors of the volume flow rate $\Delta \dot{V}$, density $\Delta \rho$, specific heat $\Delta c_{p}$, temperature difference $\delta \Delta t$ and heating surface area $\Delta A$ are $1.7 \cdot 10^{-7} \mathrm{~m}^{3} / \mathrm{s}, 0.001 \mathrm{~kg} / \mathrm{m}^{3}, 10 \mathrm{~J} /(\mathrm{kgK}), 0.2 \mathrm{~K}$ and $0.1 \mathrm{~m}^{2}$, respectively. Hence, the maximum overall experimental limits of error for the heat flux extended from $\pm 14 \%$ for the maximum heat flux up to $\pm 19 \%$ for the minimum heat flux.

\section{RESULTS AND DISCUSSION}

\subsection{Charging process}

Figure 4 shows the impact of the inlet temperature of HTF on the heat flux versus time during the charging process of the tested LHTE system. The obtained results indicate that heat transfer intensity (heat flux) increases considerably with an increase of the inlet temperature of $\mathrm{HTF}$ from $75^{\circ} \mathrm{C}$ to $85^{\circ} \mathrm{C}$. However, as it is seen in Fig. 4, the heat flux decreases about 4 times, from $80 \mathrm{~W} / \mathrm{m}^{2}$ to $20 \mathrm{~W} / \mathrm{m}^{2}$ for $t_{1}=85^{\circ} \mathrm{C}$ after $1 \mathrm{~min}$ of the charging process. For the inlet temperature of $\mathrm{HTF}$ of $75^{\circ} \mathrm{C}$ the decrease of the a heat flux is of an order of magnitude. The reason of this dramatic drop of the heat flux is a substantial difference of the thermal conductivity solid and liquid phase of stearic acid. Almost independent on inlet temperature of HTF already after $1 \mathrm{~min}$ of the charging process liquid layer appears around the helical and deteriorates heat transfer compared to the solid phase during the start stage. 


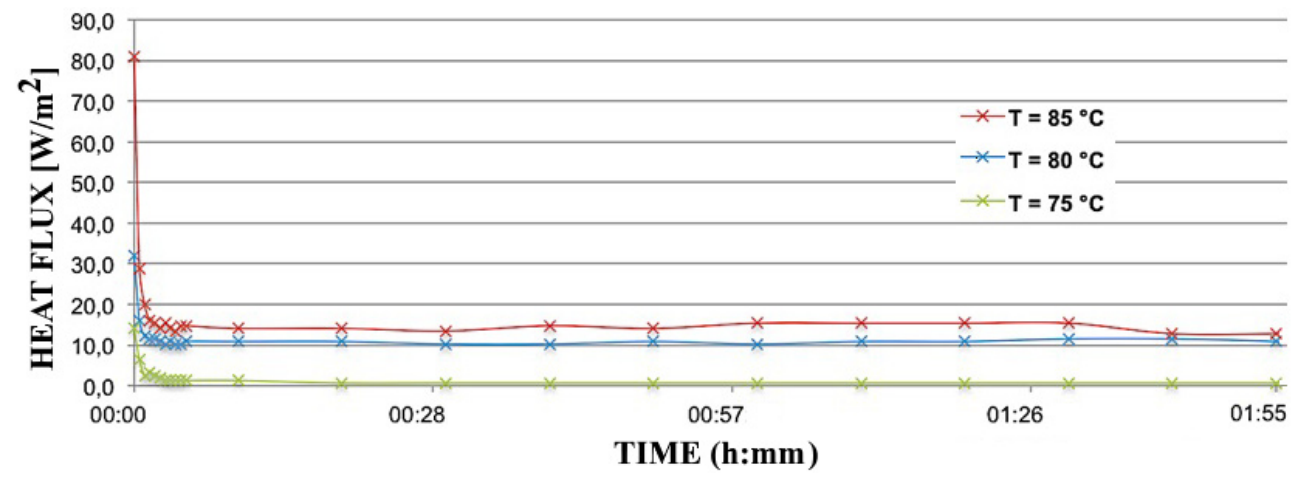

Fig. 4. Heat flux vs. time for different inlet temperatures during charging process

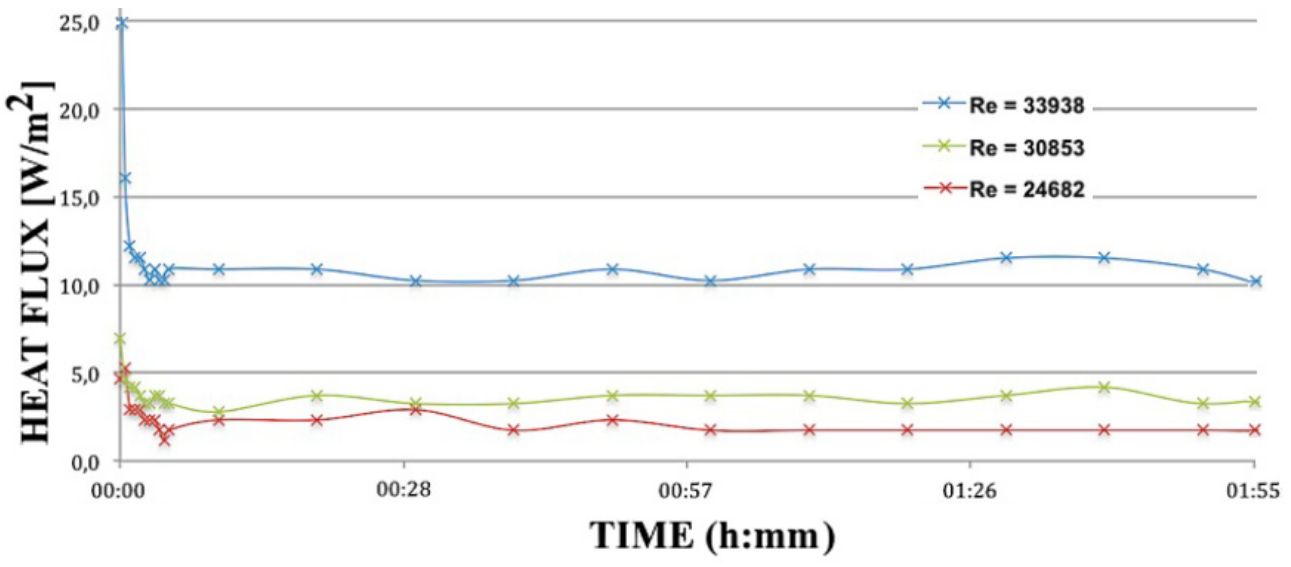

Fig. 5. Heat flux versus time for different Reynolds numbers at $\mathrm{t}_{1}=85^{\circ} \mathrm{C}$ during charging process

Figure 5 shows the influence of Reynolds number of HTF on the intensity of heat transfer (heat flux) as a function of time during the charging process. As it was expected, an increase of the Reynolds number of HTF results in a heat flux increase. Again, independent of the value of the Reynolds number, a dramatic drop of heat flux after 1 minute of the charging process is observed.

Figure 6 shows the photographs of the state of the tested PCM (stearic acid) in the cylindrical vessel. The patina can be seen on the copper helical coil almost 2 $\mathrm{h}$ after the beginning of the melting process.

\subsection{Discharging process}

Figure 7 presents the photographs of solidification stages of stearic acid against time. As it can be seen in Fig. 7a, a thick solid layer of PCM appeared around the helical coil already after 1 hour.

As an example, Fig. 8 shows the influence of the Reynolds number of HTF on the intensity of heat transfer (heat flux) as a function of time during the discharging process for the inlet temperature of HTF equal to $8.5^{\circ} \mathrm{C}$ and for three inlet temperatures of HTF during the charging process. As it is seen in Fig. 8, the

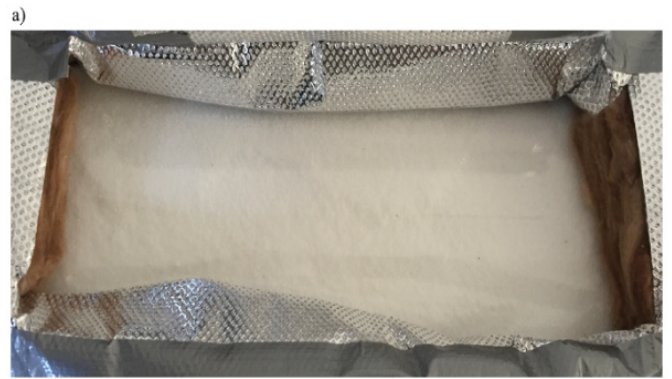

b)

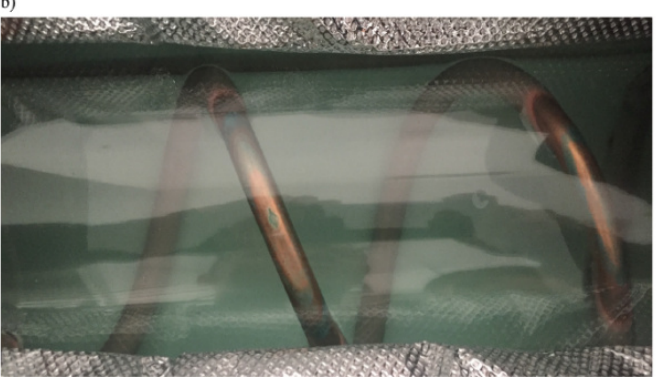

Fig. 6. Photographs of melting process with inlet temperature of $\mathrm{HTF}$ of $85^{\circ} \mathrm{C}$, a) melted stearic acid after $60 \mathrm{~min}, \mathrm{~b}$ ) melted stearic acid after $115 \mathrm{~min}$ 
influence of the inlet temperature of HTF during the charging process is negligible regarding the intensity of the heat transfer during discharging process. To some extent, the data confirm the repeatability of the charging-discharging process and the stability of the thermal process.

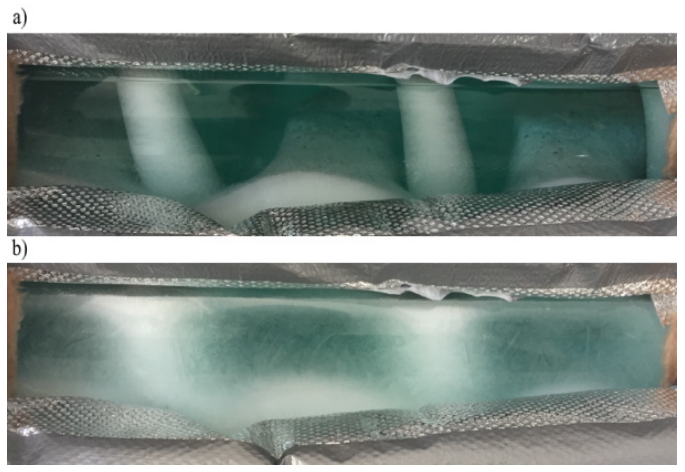

Fig. 7. Photographs of the stearic acid solidification with inlet temperature of $8.5^{\circ} \mathrm{C}$, a) solidified stearic acid after $60 \mathrm{~min}, \mathrm{~b}$ ) solidified stearic acid after $115 \mathrm{~min}$

\section{CONCLUSIONS}

1. The inlet temperature and the Reynolds number of HTF have a moderate effect on the performance of the tested LHTE system during the charging process.

2. Both inlet temperature and Reynolds number of HTF increase results in heat transfer improvement.

3. A dramatic drop of heat flux - already after $1 \mathrm{~min}$ of charging process, as a result of heat transfer deterioration due to the occurrence of a liquid layer around heating surface (helical coil) indicates the necessity of a thermal conductivity improvement of the used PCM (stearic acid) in order to intensify the whole charging process.

4. Corrosion effects were observed on the heating coil, which indicates a material (copper-stearic acid) incompatibility.

\section{Nomenclature}

Symbols

$$
\begin{array}{ll}
A & - \text { heat transfer area, } \mathrm{m}^{2} \\
c_{p} & - \text { specific heat, } \mathrm{J} / \mathrm{kgK} \\
d & - \text { diameter of copper tube, } \mathrm{m} \\
\dot{Q} & - \text { heat transfer rate, } \mathrm{W} \\
\dot{q} & - \text { heat flux, } \mathrm{W} / \mathrm{m}^{2} \\
R e & - \text { Reynolds number } \\
t_{1} & - \text { HTF inlet temperature, } \\
t_{2} & - \text { HTF outlet temperature, } \\
\dot{V} & - \text { volume flow rate, } \mathrm{m}^{3} / \mathrm{s} \\
w & - \text { velocity, } \mathrm{m} / \mathrm{s} \\
\rho & - \text { density, } \mathrm{kg} / \mathrm{m}^{3} \\
v & - \text { viscosity, } \mathrm{m}^{2} / \mathrm{s}
\end{array}
$$

\section{References}

1. Domański R. (1990), Storage of thermal energy, Państwowe Wydawnictwo Naukowe, Warszawa (in Polish)

2. Letcher T. M. (2016), Storing Energy with Special Reference to Renewable Energy Sources, Elsevier,

3. Sharma A., Tyagi V.V., Chen C.R., Buddhi D. (2013). Review on thermal energy storage with phase change materials and applications, Renewable and Sustainable Energy Reviews, Vol. 13, pp. 318-345

4. Al-Kayiem H. H., Lin S. C., Lukmon A. (2013), Review on Nanomaterials for Thermal Energy Storage Technologies, Nanoscience \& Nanotechnology-Asia, Vol. 3, pp. 60-71

5. Li T., Lee J., Wang R., Kang Y. T. (2014). Heat transfer characteristics of phase change nanocomposite materials for thermal energy storage application, International Journal of Heat and Mass Transfer, Vol. 75, pp. 1-11

6. Wu S., Fang G., Chen Z. (2012), Discharging characteristics modeling of cool thermal energy storage system with coil pipes using n-tetradecane as phase change material, Applied Thermal Engineering, Vol. 37, pp. 336-343

7. Desgrosseilliers L., Whitman C. A., Groulx D., White M. A. (2013), Dodecanoic acid as a promising phase-change material for thermal energy storage, Applied Thermal Engineering, Vol. 53, pp. 37-41

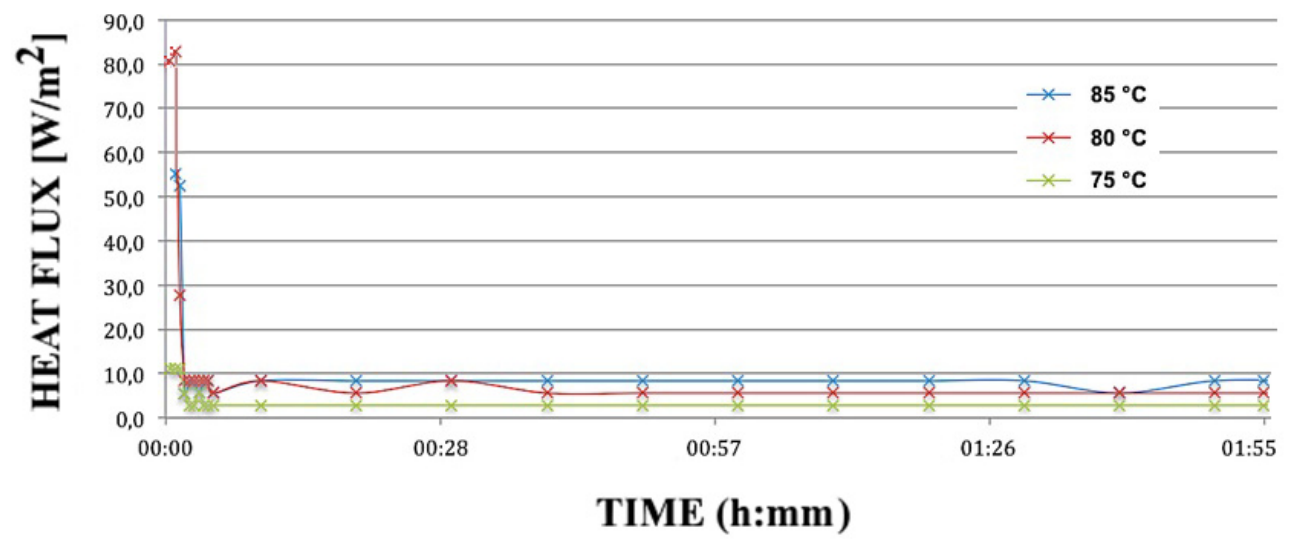

Fig. 8. Heat flux vs time for different Reynolds numbers at $\mathrm{t}_{1}=8.5^{\circ} \mathrm{C}$ during discharging process 
8. Al-Abidi A. A., Mata S., Sopiana K., Sulaimana M.Y., Mohammada A. Th. (2013), Experimental study of PCM melting in triplex tube thermal energy storage for liquid desiccant air conditioning system, Energy and Buildings, Vol. 60, 270-279

9. Shokouhmand H., Kamkari B. (2013), Experimental investigation on melting heat transfer characteristics of lauric acid in a rectangular thermal storage unit, Experimental Thermal and Fluid Science, Vol. 50, 201-212

10. Silakhori M, Metselaar H. S. C., Mahlia T. M. I., Fauzi H., Baradaran S., Naghavi M. S. (2014), Palmitic acid/polypyrrole composites as form-stable phase change materials for thermal energy storage, Energy Conversion and Management, Vol. 80 491-497

11. Hosseini M.J., Rahimi M., Bahrampoury R. (2014), Experimental and computational evolution of a shell and tube heat exchanger as a PCM thermal storage system, International Communications in Heat and Mass Transfer, Vol. 50, 128-136

12. Behzadi S., Farid M.M. (2014), Long term thermal stability of organic PCMs, Applied Energy, Vol. 122, 11-16

13. Zhang P., Xiao X., Meng Z.N., Li M. (2015), Heat transfer characteristics of a molten-salt thermal energy storage unit with and without heat transfer enhancement, Applied Energy, Vol. 137, 758-772

14. Diao Y.H., Wang S., Zhao Y.H., Zhu T.T., Li C.Z., Li F.F. (2015), Experimental study of the heat transfer characteristics of a new-type flat micro-heat pipe thermal storage unit, Applied Thermal Engineering, Vol. 89, 871882

15. Delgado M., Lázaro A., Mazo J., Peñalosa C., Dolado P, Zalba B. (2015), Experimental analysis of a low cost phase change material emulsion for its use as thermal storage system, Energy Conversion and Management, Vol. 106, 201-212

16. Cano D., Funéz C., Rodriguez L., Valverde J.L., Sanchez-Silva L. (2016), Experimental investigation of a thermal storage system using phase change materials, Applied Thermal Engineering, Vol. 107, pp. 264-270

17. Korti A., Tlemsani F. Z. (2016), Experimental investigation of latent heat storage in a coil in PCM storage unit, Journal of Energy Storage, Vol. 5, pp. 177-186

18. Motahar S, Khodabandeh R. (2016), Experimental study on the melting and solidification of a phase change material enhanced by heat pipe, International Communications in Heat and Mass Transfer, Vol. 73, $1-6$

19. Wang Y., Wang L., Xie N., Lin X., Chen H. (2016), Experimental study on the melting and solidification behavior of erythritol in a vertical shell-and-tube latent heat thermal storage unit, International Journal of Heat and Mass Transfer, Vol. 99, 770-781

20. D'Avignon K., Kummert M. (2016), Experimental assessment of a phase change material storage tank, Applied Thermal Engineering, Vol. 99, 880-891

21. Agarwal A., Sarviya R.M. (2016), An experimental investigation of shell and tube latent heat storage for solar dryer using paraffin wax as heat storage material, Engineering Science and Technology, an International Journal, Vol. 19, 619-631

22. Tayssir M., Eldemerdash S. M., Sakr R. Y., Elshamy A. R., Abdellatif O. E. (2017), Experimental investigation of melting behavior of PCM by using coil heat source inside cylindrical container, Journal of Electrical Systems and Information Technology, Vol. 4, 18-33

23. Zondag H.A., de Boera R., Smedinga S.F., van der Kamp J. (2018), Performance analysis of industrial PCM heat storage lab prototype, Journal of Energy Storage Vol. $18,402-413$

24. Neumann H., Niedermaier S., Gschwander S., Schossig P. (2018), Cycling stability of D-mannitol when used as phase change material for thermal storage applications, Thermochimica Acta, Vol. 660, 134-143

25. Kabeel A.E., El-Samadony Y.A.F., El-Maghlany W. M. (2018), Comparative study on the solar still performance utilizing different PCM, Desalination Vol. 432 89-96

26. Kabbara M., Groulx D., Joseph A. (2018), A parametric experimental investigation of the heat transfer in a coilin-tank latent heat energy storage system, International Journal of Thermal Sciences, Vol. 130 395-405

\section{Biographical notes}

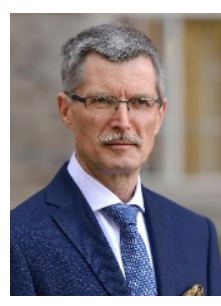

Janusz T. Cieśliński received his MSc degree in Mechanical Engineering from Gdańsk University of Technology in 1978 as well as his $\mathrm{PhD}$ degree in 1986. He also received his DSc degree (habilitation) from Gdańsk University of Technology in 1997. In 2002- 2008 he served as a vice dean of the Faculty of Mechanical Engineering. In 20062010, he was head of the Chair of Ecoengineering and Process Apparatus and in 2010-2017 he was head of the Ecoengineering and Combustion Engines Division. In 2002 2007, he was a chairman of the Multi-Phase Flow and NonNewtonian Fluids Section of the Polish Academy of Sciences. Since 2011, he is a member of the Committee of Thermodynamics and Combustion of the Polish Academy of Sciences. Since 2008 he is full professor at Gdansk University of Technology, Poland and since 2016 he is vice rector of the Gdańsk University of Technology.

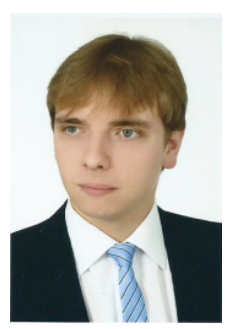

Maciej Fabrykiewicz received his MSc degree in Energy Technology from the Gdańsk University of Technology. He is a PhD student at the Faculty of Mechanical Engineering at Gdańsk University of Technology. He is interested in heat transfer intensification methods, and the application of nanofluids and nanocomposites in heat exchangers. His research is focused on the utilization of nanocomposites for the storage of thermal energy. 
